Provided for non-commercial research and education use. Not for reproduction, distribution or commercial use.

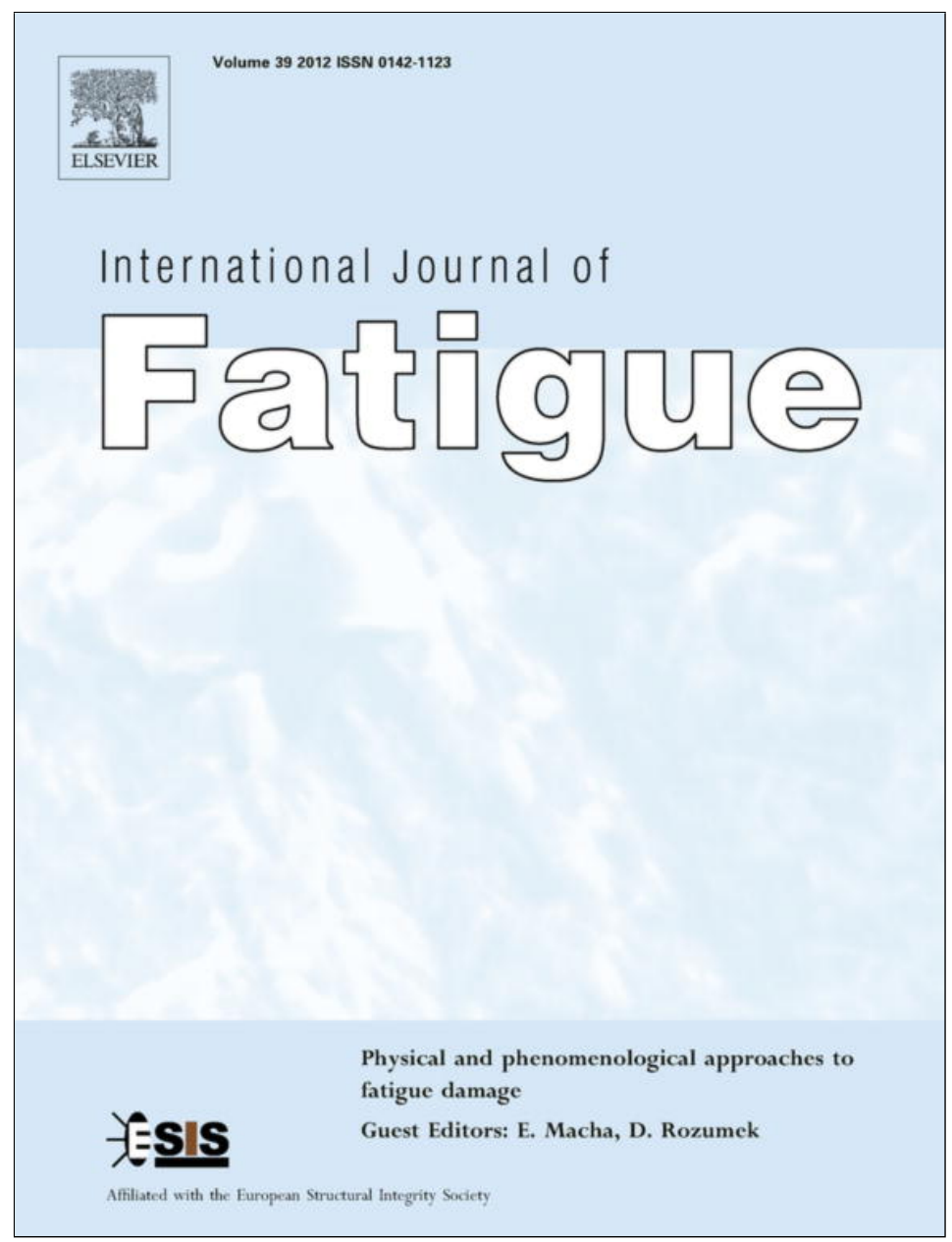

This article appeared in a journal published by Elsevier. The attached copy is furnished to the author for internal non-commercial research and education use, including for instruction at the authors institution and sharing with colleagues.

Other uses, including reproduction and distribution, or selling or licensing copies, or posting to personal, institutional or third party websites are prohibited.

In most cases authors are permitted to post their version of the article (e.g. in Word or Tex form) to their personal website or institutional repository. Authors requiring further information regarding Elsevier's archiving and manuscript policies are encouraged to visit:

http://www.elsevier.com/copyright 


\title{
Extrusion/intrusion structures as quantitative indicators of accumulated fatigue damage
}

\author{
M. Karuskevich, O. Karuskevich, T. Maslak*, S. Schepak \\ Aircraft Design Department, National Aviation University, Komarova Ave. 1, 03058 Kyiv, Ukraine
}

\section{A R T I C L E I N F O}

\section{Article history:}

Received 24 November 2010

Received in revised form 10 February 2011

Accepted 17 February 2011

Available online 22 February 2011

\section{Keywords:}

Full scale fatigue testing

Life prediction

Aluminium alloys

Damage accumulation

Fatigue initiation

\begin{abstract}
A B S T R A C T
Two approaches to aircraft fatigue monitoring by the computer-aided analysis of surface structures are described: (a) application of fatigue indicators attached to the aircraft unit; (b) the direct observation of the alclad aluminium alloys surface. The evolution of aluminium surface state has been monitored at various fatigue loading regimes. Some parameters have been used for the quantitative analysis of surface structures: (a) density of slip lines for single-crystals; (b) intensity and fractal dimensions of the deformation relief for polycrystalline aluminium. The possibility of a fatigue process prediction both at crack initiation stage and fatigue crack propagation stage is shown.
\end{abstract}

(c) 2011 Elsevier Ltd. All rights reserved.

\section{Introduction}

Due to the development of analytical and tools methods of fatigue damage accumulation monitoring the failure rate in aircraft structures caused by metal fatigue has decreased last years. Nevertheless, metal fatigue is still one of the main reasons of unforeseen crashes. Taking into consideration the importance of the problem, a set of International Civil Aviation Organization (ICAO) documents, as well as European Joint Aviation Regulations (JAR), US Federal Aviation Regulation (FAR), and Airworthiness Regulations of Russia and Ukraine consider the aircraft fatigue analysis as a mandatory procedure for providing aircraft reliability and service life.

Components that fail by fatigue usually undergo three separate stages of damage: (a) fatigue initiation; (b) propagation of the fatigue crack; (c) final sudden failure.

It is obvious that the quicker you reveal the initial stage of fatigue the less probability of disastrous failure is.

Fatigue analysis includes a set of theoretical and experimental procedures, but taking into account the complicated character of aircraft loading during operation and the stochastic nature of metal fatigue, one may assume that at present only reliable and adequate instrumental diagnostic of actual accumulated fatigue damage can prevent unexpected failure of structural components.

\footnotetext{
* Corresponding author.

E-mail addresses: mkaruskevich@hotmail.com (M. Karuskevich), maslakt@yahoo.com (T. Maslak).
}

There are two approaches to instrumental estimation of accumulated fatigue damage: (a) application of fatigue indicators (sensors, specimen-witnesses); (b) direct material state diagnostic.

A set of diagnostic methods use fatigue indicators, mounted on the surface of the object to be inspected. The indicators subjected to the spectrum of operating cyclic loads, change their state or may be even destroyed and in such a way indicate the degree of damage in the tested structural element.

Direct inspection may be performed by applying non-destructive methods, such as acoustic emission testing, high frequency ultra sonic, penetration of liquid, and eddy current test methods.

Our investigations show that quantitative estimation of fatigue damage accumulation may effectively be conducted by computer-aided optical analysis of the surface state of the metal foil indicators, attached to the investigated units or by direct observation of the aircraft skin surface state if the skin is made of alclad alloys.

\section{Single-crystal fatigue indicators}

The single-crystal fatigue damage indicator was created at the National Aviation University [1]. The quantitative parameter of the accumulated fatigue damage in this concept is the density of the slip lines on the single-crystal surface.

At the first stage of the researches the single-crystal indicator attached to the specimen was loaded by regular regime.

The persistent slip band appeared on the single-crystal surface after several thousand of cycles. 
The density of slip lines calculation was performed with light microscope with magnification $400 \times$.

The tests conducted have shown the close liner relationship between the density of slip lines and the number of cycles.

At the following stage of research programme we tried to investigate diagnostic opportunities in the more complex programme regime.

The cyclic loading was performed at two stages with transition from the lower level of loads (maximum stress of cycle equals $140 \mathrm{MPa}$ ) to the higher (maximum stress of cycle equals $180 \mathrm{MPa}$ ). After fatigue loading the single overload was applied. The magnitude of the stress under the static overload was $400 \mathrm{MPa}$.

The slip lines formed under cyclic loading were located at the angle of $82^{\circ}$ to the axis of loading. The angle of the slip lines inclination after static loading was $57^{\circ}$. This distinguishes them from the bands of fatigue nature.

Thus, the possibility to monitor damage caused by complex fatigue loading with the static overloads, was demonstrated (Fig. 1). In Fig. $1 k$ is the density of slip lines (number of lines per unit of length), $N$ - the number of cycles.

\section{Computer-aided optical analysis of intrusion/extrusion structure of alclad aluminium alloys}

For a skin of civil aircraft, aluminium alloys D16AT and V95 are widely used in Ukraine and Russia, which are almost analogous to 2024 T3 and 7075T6, according to AISI-SAE designation. The main alloying components of D16AT and 2024T3 are copper and magnesium, while V95 and 7075 T6 contain about $5 \%$ of zinc. In order to reduce the possible corrosion process, some sheets of mentioned alloys are often covered with a layer of pure aluminium (for D16AT and 2024T3) or with a layer of $\mathrm{Al}$ with $1.0 \%$ of $\mathrm{Zn}$ (for V95 and 7075T6). The thickness of clad layer is ranging from 4 to $7 \%$ of the total sheet thickness.

For polycrystalline metals as well as for single-crystals, the cyclic loading under certain conditions leads to strain localization zones called persistent slip bands. These PSB's are connected with the evolution of a dislocation substructure and the formation of extrusion/intrusion slip markings on the specimen surface. In Fig. 2 the scheme of the extrusions, intrusions and slip bands formation is presented.

Aluminium and some of its alloys, which may be used for cladding, are considered to be so called persistent slip bands (PSBs) type materials, because when they are subjected to cyclic loading, PSBs appear and develop on their surfaces [3].

Relief intensity depends on the stress level, distribution of the stress near the stress concentrator and the number of cycles.

Flat specimens with a hole in the centre, in order to induce fracture localization were used in a presented fatigue test procedure.

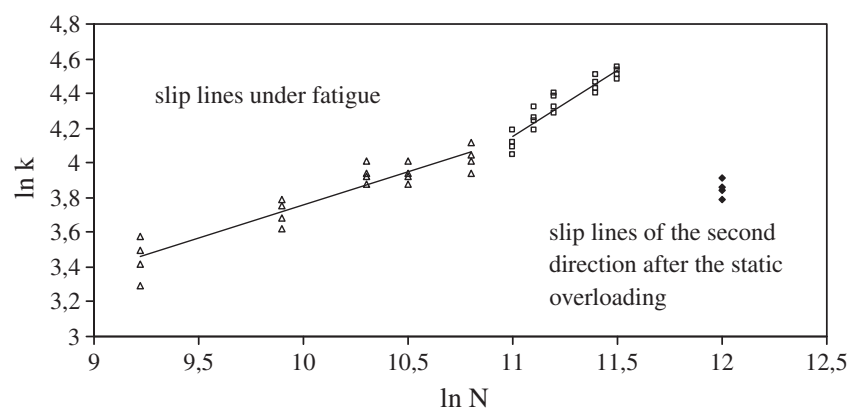

Fig. 1. Relationship between the slip lines density $(k)$ and the number of cycles, $N$.

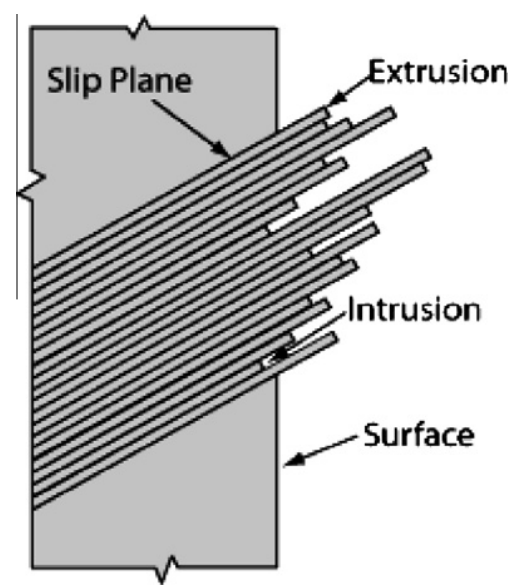

Fig. 2. The scheme of the extrusions, intrusions and slip bands formation [2].

Such stress concentrator indicates the point for optical investigation as well. The thickness of the specimen is $1.5 \mathrm{~mm}$ and the diameter of the hole is $4.0 \mathrm{~mm}$. These dimensions were chosen because sheets of $1.5 \mathrm{~mm}$ thickness are used in many cases for aircraft skin production, where as $4 \mathrm{~mm}$ hole imitates a constructive hole for rivets. In aircraft structures rivets are used to joint sheets of the skin or mount the skin on frames and stringers. The number of rivets in the structure of a modern passenger airplane for 200 passengers is more than 1.5 million. Thus, such kind of stress concentrator is typical.

Tests have been performed under wide spectrum of loads at frequency of $11 \mathrm{~Hz}$ and load ratio $R=0$.

The procedure of accumulated fatigue damage estimation used in the research includes the analysis of digital images of the deformation relief investigated by the light microscope.

Correspondence of the studied structures to the well-known scheme of the extrusion and intrusion formation [3] was proved by the scan microscope investigation.

The digital photo of the specimen surface with developed deformation relief obtained by the scan microscope SEM-515 - "Phillips" with the voltage $30 \mathrm{kV}$ is presented in Fig. 3.

The dislocation structure of deformation relief was investigated as well. It was revealed that several kinds of dislocation substructures co-exist inside the surface relief: extended dislocation substructure (Fig. 4a), chaotic dislocation in the grain (Fig. 4b), chaotic dislocations inside the strip-like dislocation (Fig. 4c), subgrain with inner block substructure (Fig. 4d), honeycomb structure (Fig. 4e).

The images of cyclically loaded specimen surfaces have been processed by special software. The developed programme saves the surface images in bmp format and gives the possibility to determine the proposed damage parameter $D$ quantitatively. Such parameter is estimated near the stress concentrator on the area approximately $0.09 \mathrm{~mm}^{2}$. Damage parameter is equal to the ratio of the surface area with deformation tracks (PSBs) to the total checked surface in the observed spot.

A set of experimental curves that express the dependence of accumulated damage parameter on the number of cycles has been obtained.

As example, the result of fatigue test of D16AT specimen and damage monitoring under the maximum stress $81.7 \mathrm{MPa}$ are presented. It expresses the relationship of damage parameter $D$ and current number of cycles $N_{C}$ (Fig. 5). The correlation and regression analysis shows that the results obtained can be approximated by the function $D=0.0027 N^{0.394}$ with determination coefficient $R^{2}=0.7865$. 


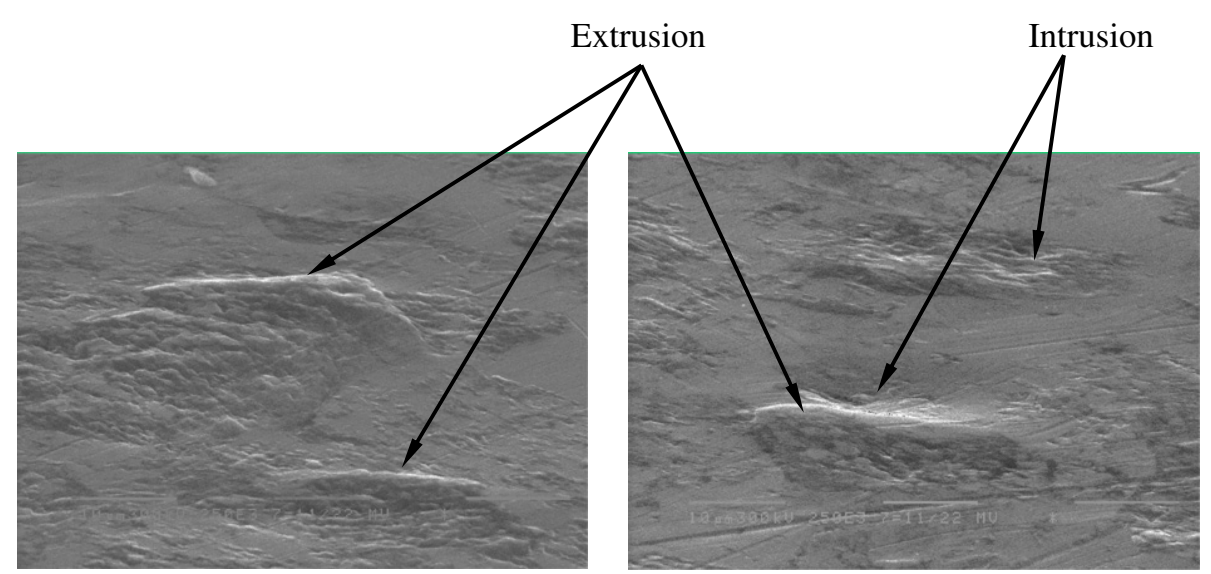

(a)

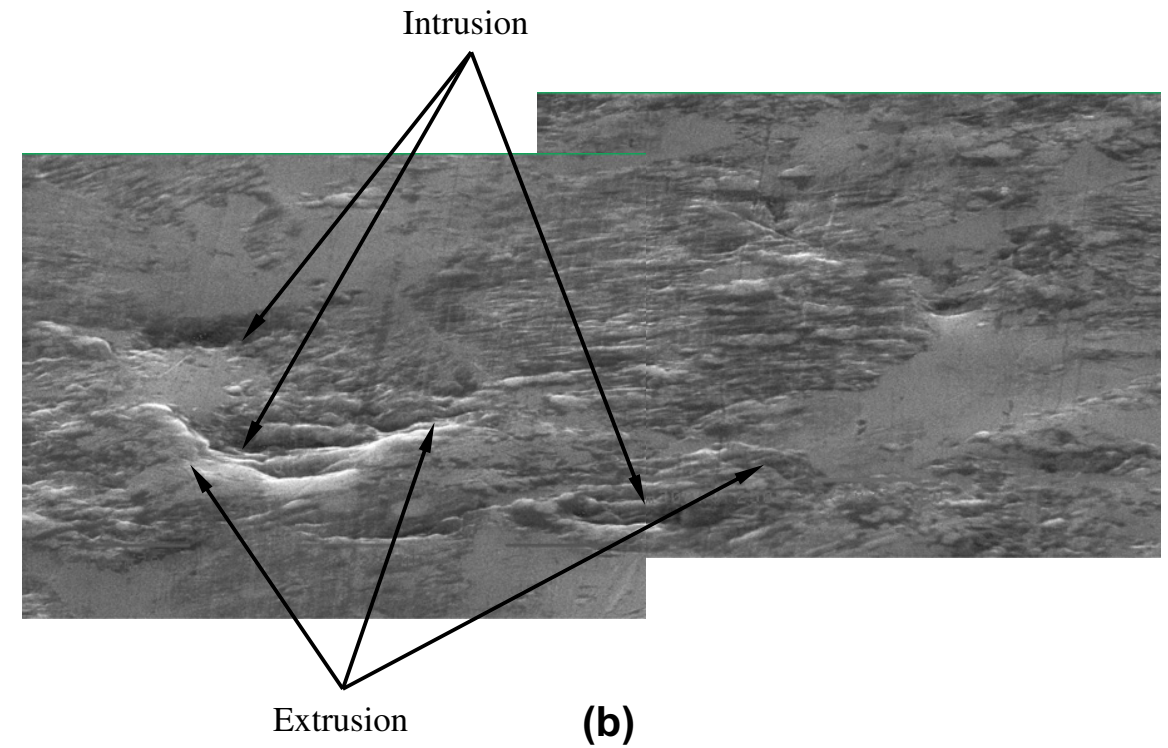

Fig. 3. The fragments of the surface of the aluminium layer of alclad alloy D16AT investigated by scan microscope SEM-515 (2500×): (a) surface relief under tension; (b) surface relief under compression.

The tests were finished after the nucleation of fatigue crack of $1.0 \mathrm{~mm}$ length, so a crack length of $1.0 \mathrm{~mm}$ has been accepted as the critical state condition.

As it is seen from the graph, the minimum scatter is on the initial stage of the fatigue process, whereas the final stage of the damage accumulation process has maximum level of scatter.

In practice indication of actual strain level under static loads is very important; therefore special investigations of surface state under static deformation have been conducted as well.

A set of specimens of aluminium alloy D16AT has been tested under maximum relative strain $0.66 ; 0.83 ; 0.85 ; 1.12 ; 1.19 ; 2.15$; 2.32; 5.22; and 12.15 percents relatively.

Formation and evolution of the deformation relief were observed, but in contrast to fatigue regimes surface pattern have been observed only under the relative strain $2 \%$ and more.

So in the case of static loads, deformation relief of alclad alloys can indicate only considerably close to ultimate strain and loads.

\section{Fractal geometry application for the analysis of intrusion/ extrusion structures}

The search of the additional criteria for deformation relief at quantitative description leads to fractal geometry [4], which is wildly used nowadays at solving the material science problems.
Fractal geometry is a mathematical concept that describes objects of irregular shape [5]. Some natural geometrical shapes, that can be irregular, rough or fragmented, can be described using concepts of fractal geometry as long as the requirement of self-similarity is satisfied. The latter term implies that the geometrical features of an object are independent of the magnification or observation scale.

So, in paper [6] some examples of fractal geometry application for the description of the processes of slip lines initiation and propagation on the single-crystals surface are presented. The evolution of fractal dimension of titanium plates (under deformation) has been investigated in paper [7]. The deformation relief of aluminium under fatigue can be considered as a self-organized structure, that is why the fractal geometry can be applied to the relief investigation.

Analysis of deformation processes results in application of fractal geometry which improves the method of optical diagnostic of surface state under the estimation of accumulated fatigue damage and prediction of residual fatigue life of structural units made of alclad aluminium alloy.

The aim of presented test is to justify experimentally the possibility of quantitative estimation of accumulated fatigue damage by the saturation parameters and fractal dimensions of deformation relief, that is forming under fatigue on the alclad alloys surface. 


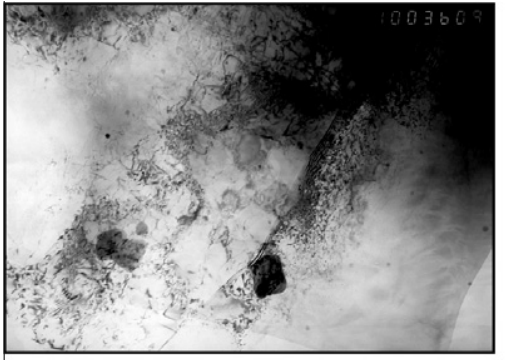

(a)

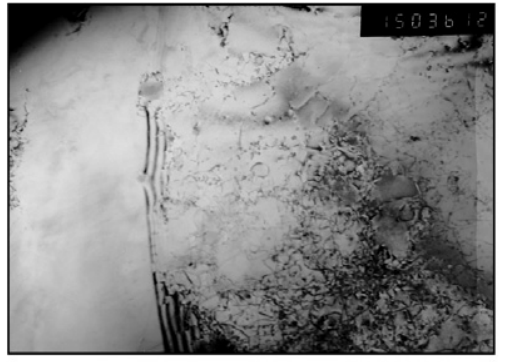

(b)

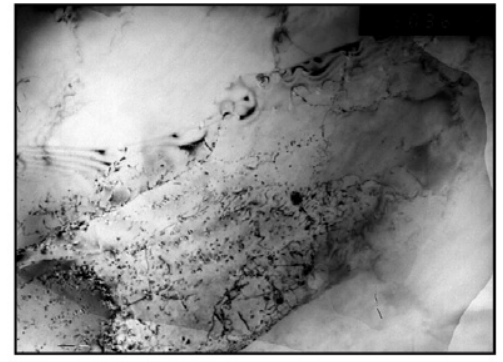

(c)

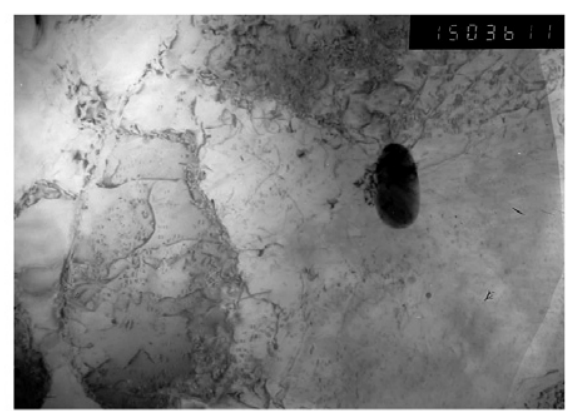

(d)

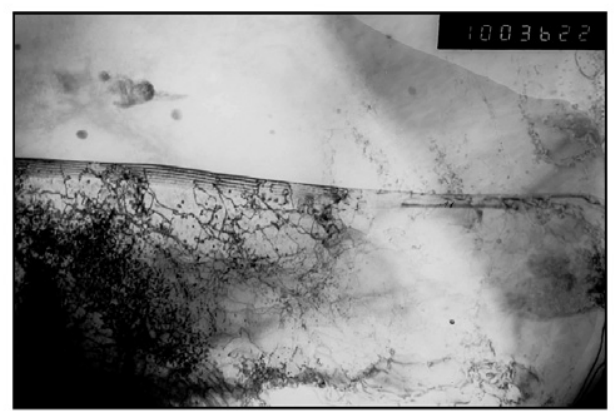

(e)

Fig. 4. Some examples of different types of dislocation structures of deformation relief $(15000 \times)$ : (a) extensive dislocation substructure, (b) chaotic dislocation in the grain, (c) chaotic dislocations inside the strip-like dislocation, (d) sub-grain with inner block substructure, (e) honeycomb structure.

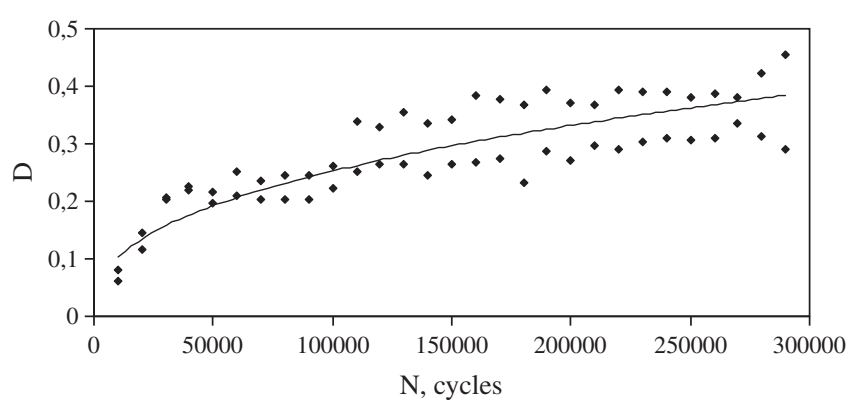

Fig. 5. The dependence of damage parameter $D$ on the number of load cycles $N$

Specimens of aluminium alloys D16AT, 2024T3 and 7075T6 have been loaded by bending with the wide range of stresses at frequency $25 \mathrm{~Hz}$. The surface was polished with diamond paste.

Nowadays there are a lot of methods of the fractal dimensions calculation for the nature objects. One of the most widespread is a "box counting" [6]. This method allows to calculate the definite types of fractal dimension.

The first possible type of fractal dimension is fractal dimension of the boundaries of deformation relief spots. This type of fractal dimension is designated as $D_{p}$.

For some fractals the most informative parameter is a fractal dimension of the ratio of perimeter to area. It is known, that this ratio characterizes the shape of objects, and for the regular geometrical figures this parameter is constant value and does not depend on the object size. At the paper [8] this type of fractal dimension was successfully used for the description of the clouds shape.

Correspondent fractal dimension for the clusters of deformation relief will be further called $D_{p / s}$.

For the data processing automation the special software has been developed.
Main stages of calculations are: transformation of digital images of a surface into the monochromic; separation of single clusters of deformation relief; determination of their contours; overlapping of the box net on the cluster's contours or on their surface (Fig. 6a), calculation of the box number, overlapping contours of clusters or their surfaces.

Final stage of fractal dimensions calculations is the construction of the corresponding graphs (Fig. 6b) and the determination of the gradients of the relationships: (a) for the fractal dimension of clusters' contours, $\ln N_{p}=f(\ln (1 / \delta))$; (b) for the clusters' surface area, $\ln N_{s}=f(\ln (1 / \delta))$; and (c) for the ratio of perimeter to area, $\ln N_{p}=f\left(\ln \left(N_{s}\right)\right)$, where $N_{p}$ is the number of cells (boxes), overlapping contours of deformation relief clusters; $N_{s}$ is number of cells overlapping the surface area of deformation relief clusters; $\delta$ is the size of the cell (Fig. 6b).

Fractal dimension $D_{p / s}$ with the application of geometrical method was estimated as a doubled absolute value of the tangent of the slope angle of the middle part of the fractal graph in its linear approximation in log-log coordinates [8].

Fractal dimensions of the deformation relief clusters contours as well as the fractal dimensions determined by the ratio of perimeter to area exceed topological dimension of the line and are within the range of $1-2$.

The design of specially constructed test machine allows carrying out optical observation of the specimen surface after initial several cycles of loading. Damage parameter $D$ and fractal dimension $D_{p / s}$ were selected as the main diagnostic parameters.

Here we consider evolution of damage parameter $D$ and fractal dimension $D_{p / s}$ during loading process of series specimens, tested under the maximum cycle stress $173 \mathrm{MPa}$ and minimum stress of the cycle $0 \mathrm{MPa}$.

The practical task of the accumulated fatigue damage monitoring is a prediction of the residual life of the aircraft structure components. In Figs. 6 and 7 the relationships between the damage parameter $D$ and fractal dimension $D_{p / s}$ with residual numbers of cycles are shown. As it is seen from the presented graphs both parameters correlate with the accumulated fatigue damage. 


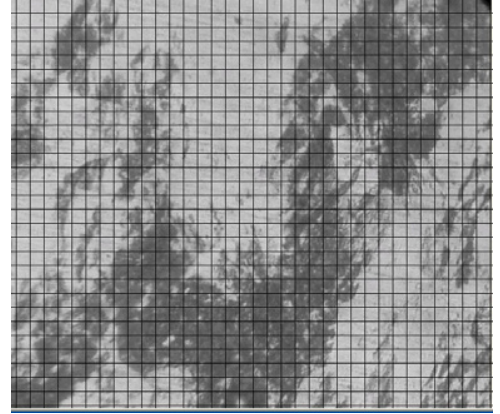

(a)

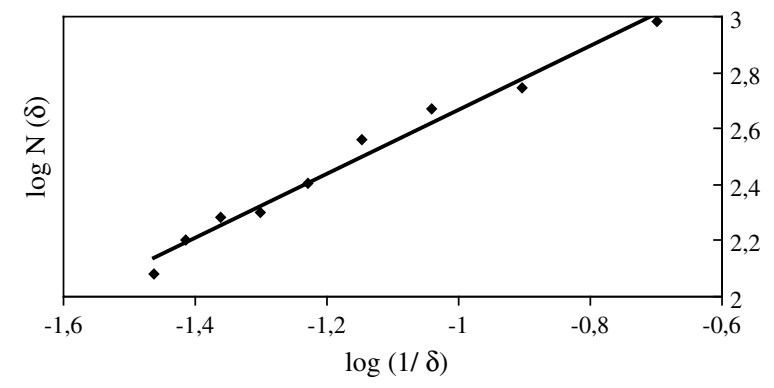

(b)

Fig. 6. Main stages of fractal dimension calculation: (a) the light microscope image of the deformation relief with the grid of boxes (500 $\times$ ); (b) exemplary graph for fractal dimension $D_{p}$ estimation as an absolute value of the tangent of the slope angle of the relationship between the number of cells necessary for the clusters' contours overlapping and the size of boxes.

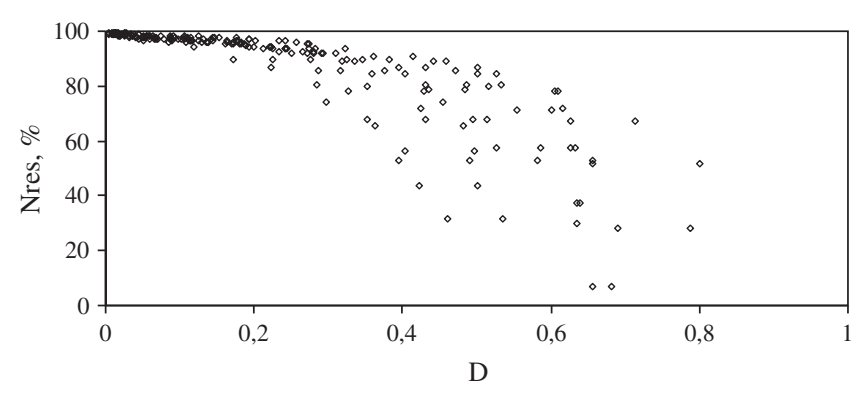

Fig. 7. Relationship between residual life and damage parameter $D$.

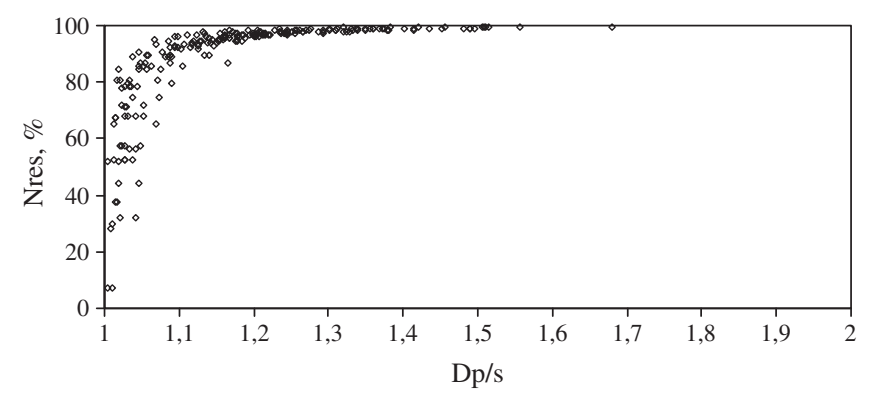

Fig. 8. Relationship between residual life and fractal dimension $D_{p / s}$.

In this relationship damage parameter $D$ points on saturation of the surface with the extrusions and intrusions that form deformation relief while changing of the fractal dimension $D_{p / s}$ characterizes the process of the deformation relief clusters coalescence.

The observed increase of data scattering is determined by attaining the saturation stage when the residual life approaches zero. It means that after attaining a certain critical level of damage parameters there is no further growth of deformation relief with increase of the number of cycles.

As it can be seen from the Figs. 7 and 8 both diagrams have almost horizontal parts. At the same time, parameters $D$ and $D_{p / s}$ complement each other. That's why multiple regression models must be used for residual life prediction.

Dispersion and regression analysis made with module "ANOVA" of the "Statgraphics Plus" has shown the possibility of the multiple correlation model application:

$N_{\text {res. }} \%,=180.346-109.588 D-56.6685 D_{p / s}$

where $D$ - damage parameter; $D_{p / s}$ - fractal dimension; $N_{\text {res. }} \%$, - the residual number of cycles, \%. 6.48 .

Correspondent value of the $R^{2}$ equals $81.4 \%$. Standard error is

Analysis performed proves the significance of both considered models parameters: damage parameter $D$ and fractal dimension $D_{p / s}$.

As a result of scheduled researches, the following exemplary programme for aircraft fatigue analysis might be proposed [9]:

1. Load operating range, load distribution along the structure, and material characteristics are determined. According to recommendations of International Civil Aviation Organization (Doc. 9051-AN/896, ICAO, 1987) the load range must be based on statistic tests data obtained by generalized load researches for the particular airplane type, and in case of insufficient data - with the help of supposed use of aircraft.

2. Structure parts to be investigated are determined. The location of possible damage can be determined by analysis or on the basis of endurance tests of the whole structure or its separate elements.

3. Laboratory fatigue tests of structure elements (specimens) with monitoring of intrusion/extrusion structures are carried out to create data bank.

The data bank (atlas) must contain test results on different load levels, different sequences of load application, etc. For each regime of loading multiple regression models that describe the relationship between D - damage parameter, Dp/s - fractal dimension and Nres. \%, - the residual number of cycles, are calculated.

4. Monitoring of fatigue process of aviation structures is performed by means of inspection of skin clad coating in areas determined according to requirements of item 2 .

5. The analysis of an inspected part of a structure is conducted by estimation of damage parameter $D$ and fractal dimensions and calculation of the residual fatigue life by the use of corresponding multiple regression models.

\section{Prediction of fatigue crack propagation by the intrusion/ extrusion structure in initial stage}

Previous results describe the possibility to predict the number of cycles till the moment of fatigue crack initiation. At present some experiment with fatigue crack monitoring allows to speak about the possibility to predict fatigue crack propagation by the intrusion/extrusion pattern at the initial stage of fracture. In fact, stochastic nature of fatigue means that the crack can start with a 


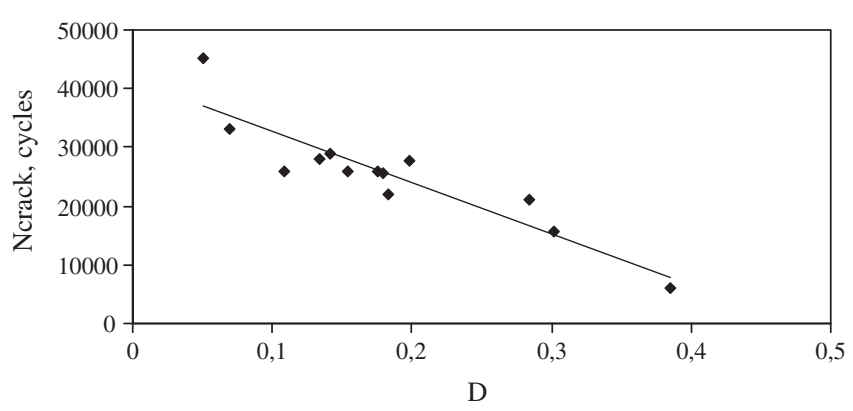

Fig. 9. Relationship between damage parameter $D$ and the number of cycles from crack nucleation to the final failure.

great scatter and this scatter depends upon many factors. In such case the level of intrusion/extrusion pattern to the moment of crack initiation can be quite different. This intrusion/extrusion structure determines the metal state in which the fatigue crack starts, so there is a reason to presume the correlation between the mentioned above parameters of surface relief and fatigue crack rate. In Fig. 9 it has been shown the relationship between parameter $D$ and the number of cycles from crack nucleation to the failure. The $D$ values are the maximum during the monitoring and correspond to the moment of fatigue crack start.

The regression analysis shows that the straight line approximation is the most appropriate for the presented data.

As the obtained results are rather optimistic, this branch of the research will extend the field of the practical application of the approach described in the paper.

\section{Conclusion}

Intrusion/extrusion structures on the surface of single-crystal and polycrystalline aluminium indicate the level of accumulated fatigue damage.

A set of experiments has proved close correlation between parameters of surface intrusion/extrusion pattern and the number of cycles for fatigue crack initiation.
Proposed approach can be applied in single-crystal fatigue sensors concept and under direct monitoring of aircraft units fatigue.

The new approach may be recommended for indication of more dangerous points of aircraft structures and for the prediction of crack under full scale fatigue testing of aircraft structures as well as for residual service life estimation.

\section{Acknowledgments}

The presented researches were parts of the projects carried out in the Aircraft Design Department at National Aviation University (Ukraine). The support of the head of the Department professor S.R. Ignatovich is greatly appreciated. We are also grateful to professor E. Zasimchuk from Institute of Metal Physic for the help and participation in the investigation of single-crystals and professor L. Markashova from E.O. Paton Electric Welding Institute for the microscopic investigation of the intrusion/ extrusion structures.

\section{References}

[1] Zasimchuk EE, Radchenko AI, Karuskevich MV. Single-crystals as an indicator of fatigue damage. Fatigue Fract Eng Mater Struct 1992;12:1281-3.

[2] NDT Resource Center. Materials and processes. Fatigue Crack Initiation: <http:// www.ndt-ed.org/EducationResources/CommunityCollege/Materials/Structure/ fatigue.htm>

[3] Goritskiy VM, Terentiev VF. Structure and fatigue fracture of metals. Moscow: Metalurgija; 1986 [in Russian].

[4] Feder J. Fractals. Moscow: Mir; 1991 [in Russian].

[5] Mandelbrot BB. The fractal geometry of nature. New York: Freeman; 1983. p. 468.

[6] Ivanova VS, Balankin AS, Bunin IZH. Synergetic and fractals in the material science. Moscow: Nauka; 1994 [in Russian].

[7] Kulkov SN, Mironov YUP. Fractal dimension of the surface under martensite deformation transformation in the nickelid of the titanium. J Tech Phys 2004;3:129-32 [in Russian].

[8] Lovejoy S. Area-perimeter relation for rain and cloud areas. Science 1982;216:185-7.

[9] Ignatovich SR, Karuskevich MV, Maslak TP. Computer aided optical method for aircraft's components fatigue life estimation. In: Multilevel approach to fracture of materials, components and structures: 17 th European conference on fracture, 2-5 Sept., 2008: abstract - Brno, Czech Republic; 2008. p. 324. 